\title{
A Study on the Relationship between Achievement Goal Orientations of Secondary School Students to Social Studies and Self-Regulation Strategies They Use
}

\section{Gökçe Kılıçoğlu'}

Gazi University, Gazi Faculty of Education, Department of Turkish and Social Sciences Education, Ankara, Turkey

Email:gokcekilicoglu@gmail.com Tel:+905357188061

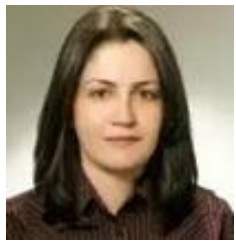

\begin{abstract}
Purpose of this study is to examine the relationship between achievement goal orientations of secondary school students to social studies (self-approach, task-approach, other-approach, taskavoidance, other-avoidance, self-avoidance) and self-regulation strategies they use (cognitive strategy, self-regulation). In addition, it has been tried to determine in the study to what extent academic achievements of the students could predict self-regulation strategies they use. Work group of the study consists of 346 secondary school students at 5th, 6th and 7 th grade students. Study has survey model. For purposes of the study, "Self-Regulation Strategies Scale" and "Social Studies Oriented Achievement Orientations Scale" were employed on the students. When examining correlation coefficients according to the findings obtained from the study, it has been found that the strongest relations are between goals to self-approach and goals to task-approach and between use of cognitive strategy and self-regulation; the weakest relations are between use of cognitive strategy and respective approach. In addition, it has been determined that selfapproach, task-approach, goals to task-avoidance and academic grade point averages predict significantly use of cognitive strategy by the students and that goals to self-approach and taskavoidance predict significantly students' use of self-regulation processes.
\end{abstract}

Keywords: Self-regulation, Self-regulation strategies, Cognitive strategy, Achievement goal orientation, Social studies, Secondry school students.

Citation | Gökçe Kıllı̧̧oğlu (2019). A Study on the Relationship between Achievement Goal Orientations of Secondary School Students to Social Studies and Self-Regulation Strategies They Use. Journal of Education and e-Learning Research, 6(1): 38-44.

History:

Received: 25 October 2018

Revised: 29 November 2018

Accepted: 9 January 2019

Published: 7 March 2019

Licensed: This work is licensed under a Creative Commons

Attribution 3.0 License (cc) Er

Publisher: Asian Online Journal Publishing Group
Funding: This study received no specific financial support.

Competing Interests: The author declares that there are no conflicts of interests regarding the publication of this paper.

Transparency: The author confirms that the manuscript is an honest, accurate and transparent account of the study was reported; that no vital features of the study have been omitted; and that any discrepancies from the study as planned have been explained.

Ethical: This study follows all ethical practices during writing.

\section{Contents}

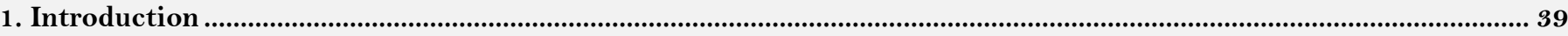

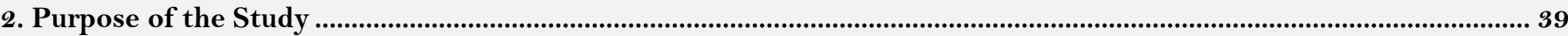

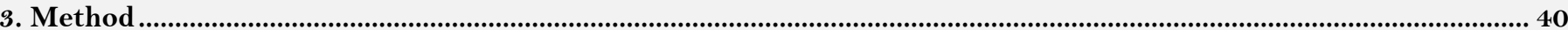

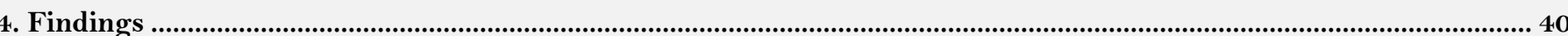

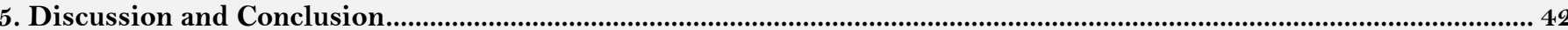

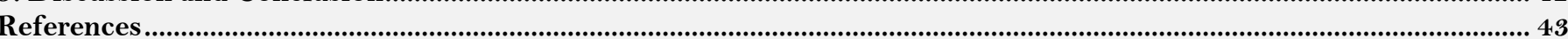




\section{Contribution of this paper to the literature}

This study contributes to the existing literature by examining the relationship between achievement goal orientations of secondary school students to social studies (self-approach, task-approach, other-approach, task-avoidance, other-avoidance, self-avoidance) and selfregulation strategies they use (cognitive strategy, self-regulation).

\section{Introduction}

At the end of $20^{\text {th }}$ century, achievement goal orientation emerged with an important theoretical perspective to ensure motivation of the students during the class expresses beliefs of individuals in the goals set to be successful and their perceptions of why they want to learn (Pintrich et al., 1991; Ames, 1992; Kaplan and Maehr, 2007). Achievement goal orientations, which examine criteria considered by the students to evaluate their beliefs and performances to succeed, also explain how students interpret their achievement and failures and their reactions under these circumstances (Zweig and Webster, 2004).

Achievement goal orientation is classified as "learning objectives" and "performance objectives" (Ames and Archer, 1988). While students having learning goal orientation focus on learning, understanding and ability and skill development, students having performance goal orientation focus on showing their skills to others and not making an low-skilled impression by taking other people as references (Kaplan and Maehr, 2007).

In 1990's, inadequacy of dual achievement goal orientation model as learning objectives and performances objectives was started to be discussed and Elliot et.al proposed triple achievement goal orientation model. While learning objective doesn't change in this model, performance orientation was considered in two sub-dimensions as "approach" and "avoidance" (Elliot and Harackiewicz, 1996; Elliot and Church, 1997; Elliot, 1999). As for the following process, learning orientation was divided into "approach" and "avoidance" and "2x2 Achievement Orientations Model” emerged (Elliot, 1999; Elliot and McGregor, 2001). According to this model, learning approach and avoidance oriented students compare their current performances having regard to their past performances while performance approach and avoidance oriented students compare themselves with others (Harackiewicz et al., 2002).

In 2011, Elliot et al. (2011) suggested “3x2 Achievement Orientations Model” including also competence concept and competence-oriented assessment which they indicate it is more effective than $2 \times 2$ achievement orientations model. Description component of competence was conceptualized as a three-dimensional structure as absolute, internal and respective in 3x2 achievement orientations model.

Students need to learn on their own and have the ability to observe their learning in order to be successful in the classes of formal education and improve themselves at today's information age after the formal education (Erdem, 2005). It can be defined as an important effect on their achievements. We can talk about many factors which can affect success of a student in the class. These factors may be related to family, school, social circle and personality of the student. In recent years, main theme of the studies conducted on academic achievement has been self-regulation concept on which learning process of the students play an effective role (Üredi and Üredi, 2005). Self-regulation is defined as active and constructive period in which students determine their own learning goals, try to organize their cognitions, motivations and behaviors and in which students are directed and limited by their goals and contextual features in the social circle (Pintrich, 2000). Important points emphasized in self-regulation play an effective role on learning periods of the students in behavioral, cognitive and motivational sense (Üredi and Üredi, 2005).

For Zimmerman (1989;1990) self-regulation strategies are processes which students consider as useful and carry out in order to get the information or skills they want to have. These processes are cognitive strategies such like self-regulation consisting of meta-cognitive strategies in order to plan, observe and change the cognition, managing the effort made by the students to perform an academic task in the class and repetition, interpretation and organization in order to learn, remember and understand (Pintrich and Groot, 1990). Self-regulation strategies are personal skills required to be improved individually in order that students could be successful in their lives. Therefore, when considering self-regulation skills as abilities which can be learnt, though and controlled, these skills are required to be supported externally (Ciltaş, 2011).

It is important in terms of long-term learning skills development and academic achievement that students would determine self-regulation strategies which express beliefs in the goals determined to be successful and achievement goal orientations revealing their perceptions for why they want to learn and processes performed to get the information or skills which they consider as useful and want to have; students follow their learning and make motivational, cognitive, affective regulations. When examining the literature, we have found studies which indicate a significant relation (Nolen and Haladyna, 1990; Ames, 1992; Ford et al., 1998; Pintrich, 2000; Schmidt and Ford, 2003; Kitsantas et al., 2009; Gul and Shehzad, 2012; Aydin and Yerdelen, 2015). When examining the literature, however, we haven't found any study which examines the relation between achievement goal orientations of the secondary school students for social studies and self-regulation strategies they use. A limited number of studies are independent studies on self-regulation strategy (Celikkaya and Kuş, 2010) and achievement goal orientation (Gezer and Şahin, 2016). This study concentrates on achievement goal orientations of the students and self-regulation strategies they use. The purpose is to make contribution to the literature by examining the relation between achievement goal orientations of the students toward social studies and self-regulation strategies they use.

\section{Purpose of the Study}

Purpose of this study is to examine the relationship between achievement goal orientations of secondary school students to social studies (self-approach, task-approach, other-approach, task-avoidance, other-avoidance, selfavoidance) and self-regulation strategies they use (cognitive strategy, self-regulation). In addition, it has been tried to determine in the study to what extent academic achievements of the students could predict self-regulation strategies they use. 


\section{Method}

\subsection{Research Model}

Survey model has been used in this study. Survey model is an approach of study that aims to describe a past or a current situation (Karasar, 1999).

\subsection{Study Group}

The study has been conducted in 2018- 2019 academic year. Students were informed on purpose of the study and assessment instruments. It was indicated that personal information of the students would be kept confidential by the researchers. It was observed that schools and classes from which the sample was chosen would have similarities. Working group of the study was composed of 346 students - 173 female and 17 male students- who studied at 6 secondary schools in Trabzon city center.

\subsection{Data Collection Tools}

\subsubsection{Self-Regulation Strategies Scale}

"Learning-Oriented Motivational Strategies Scale" consisting of 44 articles that was developed by Pintrich and Groot (1990) and adapted to Turkish by Üredi (2005) was used in the study. Evaluating of the assessment instrument was performed up to 7 grades determined between the edges "It completely suits me" and "It doesn't completely suit me". Assessment instrument is composed of two dimensions as self-regulation strategies and motivational beliefs. Self-regulation strategies of this scale consisting of two scales as cognitive strategy use (13 articles) and self-regulation (9 articles) was used as assessment instrument for this study. assessment instrument which measures frequency of occurrence of the repetition, interpretation and organization strategies in the dimension of cognitive strategies is composed of meta-cognitive strategies such like planning, monitoring, reviewing in the dimension of self-regulation, and effort managing strategies. In the study to adapt the assessment instrument to Turkish language, cronbach alpha values concerning sub-scales have been determined as .82 in scale of cognitive strategy use and .84 in self-regulation scale (Üredi, 2005). Cronbach alpha values calculated in this study are .82 in scale of cognitive strategy use and .71 in self-regulation scale.

\subsubsection{Social Studies Oriented Achievement Orientations Scale}

In the study, "Social Studies oriented Achievement Orientations Scale" developed according to 3x2 achievement orientations model developed by Gezer and Şahin (2016) was used in order to assess social studies oriented achievement orientations of secondary school students. In the scale consisting of 29 articles and six factors, the first factor is called self-approach (SA), second factor is called task-approach (TA), third factor is called other-approach (OA), fourth factor is called task-avoidance (TA), fifth factor is called other-avoidance $(\mathrm{OA})$ and sixth factor is called self-avoidance (SA). Scale form uses 5-point likert scale. Reliability coefficients calculated for the scale are: .73 for self-approach, .63 for task-approach, .71 for respective approach, .55 for task-avoidance, .73 for other-avoidance, .70 for self-avoidance. Reliability coefficients calculated for this study are .84 for self-approach, .83 for task-approach, .73 for respective approach, .78 for task-avoidance, .77 for other-avoidance, .78 for selfavoidance.

\subsection{Data Analysis}

In the study, Pearson correlation coefficient has been calculated at first and correlations of the variables have been examined. Then, sub-dimensions of goal orientations toward academic achievement and social studies have been subjected to multiple regression analysis through self-approach, task-approach, respective approach, taskavoidance, other-avoidance, self-avoidance variables in order to predict self-regulation strategies (cognitive strategy, self-regulation) used by the students.

\section{Findings}

\subsection{Descriptive Statistics and Correlations}

Self-regulation strategies used in the study and average, standard deviation values for sub-dimensions of the social studies oriented achievement orientation scales are presented in Table 1.

\begin{tabular}{l|c|c}
\hline \multicolumn{2}{c}{ Table-1. Descriptive Statistics. } & SD \\
\hline \multicolumn{1}{c}{ Variables } & Average Value & 1.09 \\
\hline 1. Use of cognitive strategies & 5.25 & .97 \\
\hline 2. Self-regulation & 4.69 & .88 \\
\hline 3. Self-Approach & 4.02 & .90 \\
\hline 4. Task-Approach & 4.27 & .96 \\
\hline 5. Other-Approach & 3.34 & .99 \\
\hline 6. Task-Avoidance & 4.02 & .98 \\
\hline 7. Other-Avoidance & 3.67 & 1.03 \\
\hline 8. Self-Avoidance & 3.58 &
\end{tabular}

When Table 1 is examined, when we discuss use of cognitive strategy ( $\mathrm{X}=5.25)$ and dimension of selfregulation $(\mathrm{X}=4.69)$ which are of sub-dimensions in the scale of self-regulation strategies for secondary school students, it is seen that it is a little bit higher value than mid-point (4) of the 7-point likert scale. When examining sub-dimensions of achievement goal orientation, it is understood that mean values are a little big higher than midpoint (3) of 5-point likert scale and that the highest goal orientations of the students is at medium level in taskapproach dimension $(\mathrm{X}=4.27)$. 
In the study, Pearson correlation coefficients have been calculated in order to examine correlations of the variables Table 2 .

\begin{tabular}{|c|c|c|c|c|c|c|c|c|}
\hline Variables & 1 & 2 & 3 & 4 & 5 & 6 & 7 & 8 \\
\hline 1. Use of cognitive strategies & 1 & $.685^{* *}$ & $.609 * *$ & $.580^{* *}$ & $.129^{*}$ & $.530^{* *}$ & $.330^{* *}$ & $.336^{* *}$ \\
\hline 2. Self-regulation & & & $.409 * *$ & $.399 * *$ & $.215^{* *}$ & $.403 * *$ & $.258 * *$ & $.292 * *$ \\
\hline 3. Self-Approach & & & & $.710^{* * *}$ & $.232^{* *}$ & $.584^{* * *}$ & $.366^{* * *}$ & $.387 * *$ \\
\hline 4. Task-Approach & & & & & $.232 * *$ & $.670^{* * *}$ & $.384^{* * *}$ & $.380 * *$ \\
\hline 5. Other-Approach & & & & & & $.317 * *$ & $.373 * *$ & $.297 * *$ \\
\hline 6. Task-Avoidance & & & & & & & $.499 * *$ & $.464^{* * *}$ \\
\hline 7. Other-Avoidance & & & & & & & & $.657 * *$ \\
\hline 8. Self-Avoidance & & & & & & & & 1 \\
\hline
\end{tabular}

Source: Data have obtained from authors' field study.

When examining correlation coefficients, it is seen that the highest correlations are between self-approach goals and task-approach goals $(\mathrm{r}=.710, \mathrm{p}<.01)$ and between use of cognitive strategy and self-regulation $(\mathrm{r}=.685$, $\mathrm{p}<.01)$ and the weakest correlation is between use of cognitive strategy and respective approach $(\mathrm{r}=.129, \mathrm{p}<.01)$. In addition, correlation of use of cognitive strategy and self-regulation to self-approach and task-approach is at a considerable level.

\subsection{Multiple Regression Analysis}

In the study, multiple regression analysis has been made using SPSS 21 program in order to determine to what extent achievement goal orientations and academic achievement of the students predict self-regulatory learning strategies. In the analysis, use of cognitive strategy and self-regulation sub-dimensions in self-regulatory learning strategies have been considered as dependent variables and academic achievement, self-approach, task-approach, respective approach, task-avoidance, other-avoidance, self-avoidance, academic achievement variables have been considered as independent variables. Results of the analysis have been specified in Table 3 and Table 4.

Table-3. Variables predicting Use of Cognitive Strategy according to Multiple Regression Analysis.

\begin{tabular}{|c|c|c|c|c|c|c|c|}
\hline Variables & B & Std. Error & $\beta$ & $\mathbf{T}$ & $\mathbf{p}$ & Bilateral r & Partial $\mathbf{r}$ \\
\hline Fixed & 1.259 & .306 & - & 4.113 & .000 & - & - \\
\hline Self-Approach & .420 & .074 & $.338 *$ & 5.699 & .000 & .609 & .296 \\
\hline Task-Approach & .227 & .077 & $.188^{*}$ & 2.935 & .004 & .580 & .158 \\
\hline Other-Approach & -.079 & .051 & -.069 & -1.552 & .121 & .129 & -.084 \\
\hline Task-Avoidance & .182 & .066 & $.165^{*}$ & 2.761 & .006 & .530 & .111 \\
\hline Other-Avoidance & .061 & .064 & .055 & .960 & .338 & .330 & .039 \\
\hline Self-Avoidance & .040 & .058 & .038 & .689 & .491 & .336 & .028 \\
\hline Academic Achievement & .115 & .047 & $.103 *$ & 2.444 & .015 & .249 & .099 \\
\hline \multicolumn{8}{|l|}{$\mathrm{R}=.671 \quad \mathrm{R}^{2}=.451$} \\
\hline $\mathrm{F}_{(7-346)}=39.612 * \mathrm{p}<.05$ & & & & & & & \\
\hline
\end{tabular}

Source: Data have obtained from authors' field study.

Table 3 illustrates results of the regression analysis concerning use of cognitive strategies by secondary school students according to self-approach, task-approach, respective approach, task-avoidance, other-avoidance, selfavoidance and academic achievement variables.

When examining data obtained as a result of multiple regression analysis in Table 3, it shows that regression model having value F 39.612 is significant. It is seen in the table that self-approach, task-approach, task-avoidance goals and academic achievement score predict significantly use of cognitive strategies by the students. When examining value $\mathrm{R}^{2}$, it is seen that $45 \%$ of use of cognitive strategies $\left(\mathrm{R}^{2}=.45\right)$ is predicted by these independent variables.

When considering standardized regression coefficients, self-approach is the first predictor of cognitive strategy use $(\beta=.338)$. In other words, students with an achievement orientation to perform a work better than the previous one (self-approach) tend to use cognitive strategies more. In addition, task-approach goals $(\beta=.188)$, taskavoidance goals $(\beta=.165)$ and academic achievement score $(\beta=.103)$ are predictors of use of the cognitive strategies. It has been determined that students, with task-approach focused on task-oriented skills in this direction, task-avoidance goal orientations focused on avoiding any failure to fulfill the task and high achievement scores, use cognitive strategies more in social studies.

When examining dual and partial correlations between predictor variables and dependent variable, there is a positive medium-level correlation $(r=, 609)$ between self-approach and use of cognitive strategies. However, when considering other variables, it is seen that correlation between two variables are still positive but at weak level $(\mathrm{r}=$,296). There is a positive medium-level correlation between task-approach and use of cognitive strategy. When checking other variables, it is seen that correlation between two variables is still positive but weak $(\mathrm{r}=, 158)$. There is a positive weak correlation between respective approach and use of cognitive strategies for the students $(\mathrm{r}=, 129)$. When checking other variables, correlation between two variables has been calculated as $r=, 084$. There is a positive medium-level correlation between task-avoidance and use of cognitive strategies for the students $(\mathrm{r}=, 530)$. When checking other variables, however, it is seen that correlation between two variables is still positive but at weak level $(\mathrm{r}=, 111)$. There is a positive medium-level correlation between other-avoidance and use of cognitive strategies for the students $(\mathrm{r}=$,330). When checking other variables, however, it has been determined that correlation between two variables is still positive but at weak level $(\mathrm{r}=, 039)$. There is a positive medium-level correlation between self-avoidance and use of cognitive strategies for the students $(r=, 336)$. When checking other 
variables, however, it is seen that correlation between two variables is still positive but at weak level $(r=, 028)$. There is a positive weak-level correlation between academic achievement score and self-sufficiency scores of the students $(\mathrm{r}=$,249). When checking other variables, however, correlation between two variables has been calculated as $\mathrm{r}=, 099$.

Table-4. Variables predicting Self-Regulation Processes according to Multiple Regression Analysis.

\begin{tabular}{l|c|c|c|c|c|c|c}
\hline Variables & $\mathbf{B}$ & Std. Error & $\boldsymbol{\beta}$ & $\mathbf{T}$ & $\mathbf{p}$ & Bilateral r & Partial r \\
\hline Fixed & 2.110 & .323 & - & 6.535 & .000 & - & - \\
\hline Self-Approach & .205 & .078 & $.185^{*}$ & 2.632 & .009 & .409 & .142 \\
\hline Task-Approach & .115 & .082 & .108 & 1.416 & .158 & .399 & .077 \\
\hline Other-Approach & .080 & .053 & .079 & 1.506 & .133 & .215 & .082 \\
\hline Task-Avoidance & .156 & .070 & $.160^{*}$ & 2.247 & .025 & .403 & .121 \\
\hline Other-Avoidance & -.023 & .067 & -.023 & -.337 & .736 & .258 & -.018 \\
\hline Self-Avoidance & .090 & .061 & .096 & 1.465 & .144 & .292 & .079 \\
\hline Academic Achievement & .030 & .050 & .030 & .597 & .551 & .118 & .032 \\
\hline $\mathrm{R}=.475$ & & & & & & & \\
\hline $\mathrm{F}$ & & & & & & & \\
\hline
\end{tabular}

When examining results obtained as a result of multiple regression analysis in Table 4 , it is seen that regression model of value F 14.091 is significant. It is seen in the table that self-approach and task-avoidance goals predict significantly self-regulation processes of the students. When examining $\mathrm{R}^{2}$ value, it is seen that $22 \%$ of use of self-regulation processes $\left(\mathrm{R}^{2}=.22\right)$ is predicted by these independent variables.

When considering standardized regression coefficients, self-approach is the first predictor for use of selfregulation processes $(\beta=.185)$. In other words, students with an achievement orientation to perform a work better than the previous one (self-approach) use self-regulation processes more.

When examining dual and partial correlations between predictor variables and dependent variable, there is a positive medium-level correlation $(r=, 409)$ between self-approach and self-regulation processes. However, when examining other variables, correlation between two variables has been calculated as $\mathrm{r}=$, 142, in other words, it is still positive but at weak level. There is a positive medium-level correlation between task-approach and selfregulation processes $(\mathrm{r}=, 399)$. When checking other variables, it is seen that correlation between two variables is still positive but weak $(\mathrm{r}=, 077)$. There is a positive weak correlation between respective approach and use of selfregulation processes for the students $(r=, 215)$. When checking other variables, however, correlation between two variables has been calculated as $r=$, 082. There is a positive medium-level correlation between task-avoidance and use of self-regulation processes for the students $(r=, 403)$. When checking other variables, however, it is seen that correlation between two variables is still positive but at weak level $(\mathrm{r}=, 121)$. There is a positive weak-level correlation between other-avoidance and use of self-regulation processes for the students $(r=, 258)$. When checking other variables, however, correlation between two variables has been calculated as $r=-, 018$. There is a positive weak-level correlation between self-avoidance and use of self-regulation processes for the students $(\mathrm{r}=, 292)$. When checking other variables, however, it is seen that correlation between two variables is still positive but at weak level $(\mathrm{r}=$, 079). There is a positive weak-level correlation between academic achievement scores and self-regulation processes for the students $(r=, 118)$. When checking other variables, however, correlation between two variables has been calculated as $\mathrm{r}=$, 032 .

\section{Discussion and Conclusion}

In this study, correlation between achievement goal orientations of secondary school students to social studies (self-approach, task-approach, other-approach, task-avoidance, other-avoidance, self-avoidance) and self-regulation strategies they use (cognitive strategy, self-regulation) has been examined. In this context, according to the results obtained from the study, it has been determined that self-approach, task-approach, goals to task-avoidance and academic grade point averages predict significantly use of cognitive strategy by the students and that goals to selfapproach and task-avoidance predict significantly students' use of self-regulation processes. Use of cognitive strategies by the students is predicted at first by learning-based self-approach which is one of the sub-dimensions of achievement goal orientation. Self-approach is predicted by task-approach and task-avoidance, respectively. From this finding of the study, we can say that students who concentrate on learning, skill development and specializing use cognitive strategies more than other students. In learning environment, a student who set a learning goal consciously and devote this goal to learn new things, develop what he learnt, be an expert in that field and be successful can manage his own cognitive management better in direction of these goals (Pamuk and Elmas, 2015).

For Pintrich (2000) goals of the students to learn direct their behaviors under the circumstances related to achievement. As for achievement goal orientation, it indicates beliefs of the students towards the goals set to be successful as an individual and their own perceptions why they want this achievement (Pintrich et al., 1991; Ames, 1992). It is important for the individual to evaluate, observe, inspect and examine his own learning while fulfilling a task and determine the best strategy suitable for the subject and himself. Success of the students in the class would increase if they use cognitive strategies consisting of repetition, elaboration, organization and critical thinking and set realistic goals to reach. One of the results obtained from the study is academic achievement is one of the predictors for use of cognitive strategies by the students and there is a positive correlation between them. Similar with this result of the study, Üredi and Üredi (2005) and Dursun and Ünver (2017) demonstrated in their study that there is a significant correlation between use of cognitive strategy and academic achievement and they indicated that achievement level of the students increases as use of cognitive strategy increases. It can be said from this result of the study that students with high achievement scores use cognitive strategies more in the social studies class.

Pintrich (2000); Risemberg and Zimmerman (1992) indicated that students with self-regulation skills could set effective goals personally, they trust on themselves to achieve these goals and use these mega-cognitive strategies 
more effectively again in order to achieve these goals. As a result of the study, it has been concluded that selfapproach goal orientation is the first predictor of use of self-regulation processes. In other words, students with an achievement orientation to perform a work better than the previous one (self-approach) use self-regulation processes more. This result of the study has parallels with result of the study conducted by Pamuk and Elmas (2015). Pamuk and Elmas concluded that learning approach goals (self-approach) explain meta-cognitive selfregulation in a positive manner in the study in which they examined role of self-sufficiencies and goal orientations of the $7^{\text {th }}$ grade students in science class to explain their mega-cognitive self-regulation skills. Again, Al-Harthy et al. (2010) concluded in their study that there is a positive correlation between learning approach goal and metacognitive self-regulation. Aydın and Yerdelen (2015) indicated in their study that learning approach goal predicts significantly use of meta-cognitive strategies. Studies by Schmidt and Ford (2003); Gul and Shehzad (2012) are other studies in which results parallel to this study were obtained. A study who set a learning approach goal is supposed to be more eager to learn a subject and understand the subject given. It is an expected situation that such a student uses meta-cognitive self-regulation strategies better (Middleton and Midgley, 1997; Al-Harthy et al., 2010). It is one of the results obtained from the study that task-avoidance goal orientation is another predictor for use of self-regulation processes.

As a result of the study, it has been determined that there is usually a positive correlation between use of cognitive strategy and use of cognitive strategy and learning-approach goals. Nolen and Haladyna (1990); Ford et al. (1998); Schmidt and Ford (2003); Aydın and Yerdelen (2015) indicate in their studies that there is a positive correlation between use of meta-cognitive strategy and learning-approach goals. One of the results obtained in this study is that there is a positive correlation between other-avoidance and cognitive strategy and use of selfregulation processes which are sub-dimensions of self-regulation strategies for performance goals. In other words, students who avoid failing in social studies class, refrain from show a worse performance than other students in the class and consider other students as a criterion of being successful or unsuccessful could observe and plan learning processes. There are a limited number of studies in the literature concerning avoidance goal orientations. Results of these studies are different from each other. While Schmidt and Ford (2003); Al-Harthy et al. (2010) found in their studies that there is a negative correlation between performance avoidance and meta-cognitive self-regulation, Coutinho and Neuman (2008) and Aydın and Yerdelen (2015) found that there is a positive but low-level correlation. We can say from these finding of the study that further studies are required in order to deduce more clearly on the direction of this correlation. It has been determined as a result of the study that there is usually a positive correlation between use of cognitive strategies and use of meta-cognitive strategies and learning-approach goals. Ford et al. (1998); Nolen and Haladyna (1990); Schmidt and Ford (2003); Aydın and Yerdelen (2015) indicate that there is a positive correlation between use of mega-cognitive strategies and learning-approach goals.

Sense of education based on getting information and producing information features assumption that individual could organize his learnings. Individual, who has to keep up with the age and change, takes responsibility primarily in his learning process and projects, organizes and evaluates his learning process because of his responsibility (Yamaç, 2011). Achievement goal orientation and self-regulatory learning strategies are main factors which affect success of the student in a positive sense. Social studies teachers at secondary schools are required to organize learning environments in a way that students could develop self-regulatory learning strategies and to pay attention to achievement goal orientations which indicate beliefs of the students in the goals they set to be successful and achievement goal orientations indicating why they this achievement.

\section{References}

Al-Harthy, I.S., C.A. Was and R.M. Isaacson, 2010. Goals, efficacy and metacognitive self-regulation a path analysis. International Journal of Education, 2(1).Available at: https://doi.org/10.5296/ije.v2i1.357.

Ames, C., 1992. Classrooms: Goals, structures, and student motivation. Journal of Educational Psychology, 84(3): 261-271.Available at: https://doi.org/10.1037//0022-0663.84.3.261.

Ames, C. and J. Archer, 1988. Achievement goals in the classroom: Students' learning strategies and motivation processes. Journal of Educational Psychology, 80(3): 260-267.Available at: https://doi.org/10.1037/0022-0663.80.3.260.

Aydin, S. and S. Yerdelen, 2015. An investigation of the relation of high school student's metacognitive strategy use in biology to achievement goal orientation and self-efficacy. Journal of Mersin University Education Faculty, 11(3): 781-792.

Celikkaya, T. and Z. Kuş, 2010. The frequency of students' usage of learning strategies in social study course. Ahmet Keleşoğlu Education Faculty (AKEF) Journal, 29: 321-336

Ciltaş, A., 2011. A study on the importance of self-regulation teaching in education. Mehmet Akif Ersoy University Journal of Social Sciences Institute, 3(5): 1-11.

Coutinho, S. and G. Neuman, 2008. A model of metacognition, achievement goal orientation, learning style and self-efficacy. Learning Environments Research, 11(2): 131-151.Available at: https://doi.org/10.1007/s 10984-008-9042-7.

Dursun, S. and G. Ünver, 2017. Self-regulated learning strategies, self-regulated learning strategies; the relationship between self-regulatory learning strategies, epistemological beliefs, academic self-concept and mathematical achievement \& 93. Turkish Journal of Computer and Mathematics Education, 8(1): 83-102.

Elliot, A., 1999. Approach and avoidance motivation and achievement goals. Educational Psychologist, 34(3): 169-189.Available at: https://doi.org/10.1207/s15326985ep3403_3.

Elliot, A. and M. Church, 1997. A hierarchical model of approach and avoidance achievement motivation. Journal of Personality and Social Psychology, 72(1): 218-232.Available at: https://doi.org/10.1037//0022-3514.72.1.218.

Elliot, A. and J. Harackiewicz, 1996. Approach and avoidance achievement goals and intrinsic motivation: A mediational analysis. Journal of Personality and Social Psychology, 7O(3): 461-475.Available at: https://doi.org/10.1037//0022-3514.70.3.461.

Elliot, A. and H. McGregor, 2001. A $2 \times 2$ achievement goal framework. Journal of Personality and Social Psychology, 80(3): 501519.Available at: https://doi.org/10.1002/pits.21760.

Elliot, A., K. Murayama and R. Pekrun, 2011. A 3× 2 achievement goal model. Journal of Educational Psychology, 103(3): 632-648.

Erdem, A., 2005. Effective ways of learning: Learning strategies and teaching. Elementary Education Online, 4(1): 1-6.

Ford, J.K., E. Smith, D. Weissbein, S. Gully and E. Salas, 1998. Relationships of goal orientation, metacognitive activity, and practice strategies with learning outcomes and transfer. Journal of Applied Psychology, 83(2): 218-233.Available at: https://doi.org/10.1037//OO21-9010.83.2.218.

Gezer, M. and F.İ. Şahin, 2016. Social studies oriented achievement goal scale (soags): Validity and reliability study. Journal of Measurement and Evaluation in Education and Psychology, 7(2): 335-354.

Gul, F. and S. Shehzad, 2012. Relationship between metacognition, goal orientation and academic achievement. Procedia-Social and Behavioral Sciences, 47: 1864-1868.Available at: https://doi.org/10.1016/j.sbspro.2012.06.914. 
Harackiewicz, J., K. Barron, J. Tauer and A. Elliot, 2002. Predicting success in college: A longitudinal study of achievement goals and ability measures as predictors of interest and performance from freshman year through graduation. Journal of Educational Psychology, 94(3): 562-575.Available at: https://doi.org/10.1037//0022-0663.94.3.562.

Kaplan, A. and M. Maehr, 2007. The contributions and prospects of goal orientation theory. Educational Psychology Review, 19(2): 141184.Available at: https://doi.org/10.1007/s 10648-006-9012-5.

Karasar, N., 1999. Scientific research method. Ankara: Nobel Publication Distribution.

Kitsantas, A., S. Steen and F. Huie, 2009. The role of self-regulated strategies and goal orientation in predicting achievement of elementary school children. International Electronic Journal of Elementary Education, 2(1): 65-81.

Middleton, M. and C. Midgley, 1997. Avoiding the demonstration of lack of ability: An underexplored aspect of goal theory. Journal of Educational Psychology, 89(4): 710-718.Available at: https://doi.org/10.1037/0022-0663.89.4.710.

Nolen, S. and T. Haladyna, 1990. Personal and environmental influences on students' beliefs about effective study strategies. Contemporary Educational Psychology, 15(2): 116-130.Available at: https://doi.org/10.1016/0361-476x(90)90011-o.

Pamuk, Ş. and R. Elmas, 2015. Prediction of metacognitive self-regulation with self-efficacy and achievement goals: Example on afyon province. Amasya Education Journal, 4(2): 175-189.

Pintrich, P. and D.E. Groot, 1990. Motivational and self-regulated learning components of classroom academic performance. Journal of Educational Psychology, 82(1): 33-40.Available at: https://doi.org/10.1037//0022-0663.82.1.33.

Pintrich, P.R., 2000. The role of goal orientation in self-regulated learning. Handbook of self-regulation. San Diego: Academic Press, pp: $452-502$.

Pintrich, P.R., D. Smith, T. Garcia and W. McKeachie, 1991. A manual for the use of the motivated strategies for learning questionnaire (mslq). Ann Arbor: University of Michigan.

Risemberg, R. and B. Zimmerman, 1992. Self-regulated learning in gifted students. Roeper Review, 15(2): 98-101.Available at: https://doi.org/10.1080/02783199209553476.

Schmidt, A. and J.K. Ford, 2003. Learning within a learner control training environment: The interactive effects of goal orientation and metacognitive instruction on learning outcomes. Personnel Psychology, 56(2): 405-429.Available at: https://doi.org/10.1111/j.1744-6570.2003.tb00156.x.

Üredi, I., 2005. Thecontributionsof perceived parenting styles to 8th class pimarystudents' self regulated learning strategies and motivational beliefs (unpublished doctoral thesis). Yıldız Teknik University, İstanbul.

Üredi, I. and L. Üredi, 2005. The predictive power of self-regulation strategies and motivational beliefs on mathematics achievement of primary school 8th grade students. Mersin University Journal of the Faculty of Education, 1(2): 250-260.

Yamaç, A., 2011. Examination of the relationships between primary fifth graders' self-regulated learning strategies and attitudes toward mathematics and mathematics Achievement. (Unpublished Master Thesis). Afyon KocatepeUniversity, Afyon.

Zimmerman, B., 1989. A social cognitive view of self-regulated academic learning. Journal of Educational Psychology, 81(3): 329339.Available at: https://doi.org/10.1037/0022-0663.81.3.329.

Zimmerman, B., 1990. Self-regulated learning and academic achievement: An overview. Educational Psychologist, 25(1): 3-17.Available at: https://doi.org/10.1207/s15326985ep2501_2.

Zweig, D. and J. Webster, 2004. Validation of a multidimensional measure of goal orientation. Canadian Journal of Behavioural Science/Revue canadienne des sciences du comportement, 36(3): 232-243. 